\title{
Cancer screening and treatment in patients with end-stage renal disease: remaining issues in the field of onco-nephrology
}

\author{
Yuichiro Kitai ${ }^{1}$, Takeshi Matsubara ${ }^{1}$, Taro Funakoshi², Takahiro Horimatsu², Manabu Muto ${ }^{2}$ and Motoko Yanagita ${ }^{{ }^{*}}$
}

\begin{abstract}
Onco-nephrology is a rapidly growing field that has recently garnered significant attention. Although the risk of developing cancer is reported to be higher in patients with end-stage renal disease (ESRD) than in the general population, the screening protocol and the treatment of cancer in ESRD patients have not yet been established. Recent studies have suggested that cancer screening in dialysis patients would be ineffective from a cost and survival benefit perspective. Nevertheless, the ESRD population is heterogeneous, including patients of varying age and comorbidity, and it is essential to identify those who would benefit from cancer screening. Once patients with ESRD are diagnosed with cancer, anti-cancer treatment should be initiated. However, a treatment strategy has not yet been established. Although many drugs require dose adjustments in hemodialysis patients, data on the pharmacokinetics of anti-cancer agents in these patients remain scarce. This review addresses the recent evidence of cancer risk and screening in the ESRD population and the pharmacokinetics of anti-cancer agents in hemodialysis patients.
\end{abstract}

Keywords: Onco-nephrology, Cancer risk, Cancer screening, Pharmacokinetics, Dialysis, End-stage renal disease

\section{Background}

Onco-nephrology is a new and evolving subspecialty that connects two different areas, oncology and nephrology. Improvement in cancer therapies has led to an increase in the number of cancer survivors, some of whom develop acute and chronic kidney complications. A better understanding of cancer-associated kidney complications, such as paraneoplastic glomerulopathies and chemotherapy-associated kidney diseases, is thus required to enable oncologists and nephrologists to treat patients suffering from cancer and kidney disease [1-3]. The term "onco-nephrology" usually relates to acute and chronic kidney complications that arise due to cancer or cancer treatment. In order to provide evidence-based care for patients with cancer and kidney disease, however, the issues on how to manage cancer in patients with end-stage renal disease (ESRD) should be incorporated into the field of onco-nephrology. As discussed

\footnotetext{
* Correspondence: motoy@kuhp.kyoto-u.ac.jp

'Department of Nephrology, Graduate School of Medicine, Kyoto University,

54 Shogoin-Kawaracho, Sakyo-ku, Kyoto 606-8507, Japan

Full list of author information is available at the end of the article
}

below, two important issues remain unsolved in this field (Table 1).

The first issue relates to cancer screening in patients with ESRD. Since patients with ESRD are at a higher risk of cancer than the general population $[4,5]$, there is an urgent need to establish cancer-screening protocols for patients with ESRD. Previous studies have failed to demonstrate a substantial increase in life expectancy from cancer screening in patients with ESRD [6, 7]. These studies reported that this conclusion should be tempered when cancer screening is applied to individual patients, however, since the ESRD population is heterogeneous, and includes patients who are expected to have a long life expectancy as well as patients with a limited life expectancy as a result of advanced age or severe comorbidities. In order to establish ways to identify individuals who should receive cancer screening in this population, the frequency of cancer, the cost and effectiveness of screening tests, and patient life expectancy all need to be taken into consideration.

The second issue is that it is essential to establish treatment recommendations for ESRD patients diagnosed with 
Table 1 Areas of special importance in the field of onco-nephrology

\begin{tabular}{|c|c|}
\hline Areas & Comments \\
\hline & The representative areas in $(A) \sim(C)$ can be described as follows (the details were reviewed previously [1]). \\
\hline \multirow{4}{*}{$\begin{array}{l}\text { (A) Acute kidney injury in cancer } \\
\text { patients }\end{array}$} & The causes of AKI in cancer patients can be categorized as prerenal, intrinsic, and postrenal. \\
\hline & - Prerenal (extracellular fluid depletion, hypercalcemia, hepatic sinusoidal occlusive syndrome, drugs) \\
\hline & $\begin{array}{l}\text { - Intrinsic (acute tubular necrosis, lymphomatous infiltration of the kidney, cast nephropathy, tumor lysis } \\
\text { syndrome, thrombotic microangiopathy, secondary glomerulopathies) }\end{array}$ \\
\hline & $\begin{array}{l}\text { - Postrenal (extrarenal obstruction due to primary disease, retroperitoneal lymphadenopathy, } \\
\text { retroperitoneal fibrosis) }\end{array}$ \\
\hline \multirow[t]{2}{*}{ (B) Paraneoplastic glomerulopathies } & - Solid malignancy-associated membranous nephropathy \\
\hline & - Hematologic malignancy-associated minimal change disease \\
\hline \multirow{5}{*}{$\begin{array}{l}\text { (C) Chemotherapy-associated kidney } \\
\text { manifestations }\end{array}$} & - Minimal change disease and focal segmental glomerulosclerosis (interferon, pamidronate) \\
\hline & - Acute tubular necrosis and electrolyte wasting (cisplatin) \\
\hline & - Magnesium wasting (cetuximab) \\
\hline & - Thrombotic microangiopathy (bevacizumab, tyrosine kinase inhibitors, and gemcitabine) \\
\hline & - Cast nephropathy (methotrexate) \\
\hline
\end{tabular}

(D) Cancer risk and screening in patients with ESRD
Although the etiologies of cancer-associated renal diseases in $(A) \sim(C)$ are relatively well understood, the protocols of the cancer screening and effective anti-cancer treatment for ESRD patients are not established yet. cancer. The coexistence of ESRD with cancer reduces the likelihood that cancer patients will receive optimal anticancer therapy and supportive care. Chemotherapy might be withheld because they are undergoing hemodialysis (HD). A lack of information concerning chemotherapy in patients with ESRD also leads to the improper use of anticancer agents and severe adverse effects in these patients [8]. Data on renal or dialysis clearance for these agents remain scarce, although the number of case studies that include pharmacokinetic data and information related to the safety and efficacy of these agents has gradually increased in recent years. It is essential to find dose adjustment models and to modify existing chemotherapy protocols adequately for HD patients.

This review updates the information on cancer screening and the pharmacokinetics of anti-cancer agents in patients with ESRD.

\section{Cancer risk in patients with ESRD}

Observational studies have suggested an increased cancer risk in patients with ESRD [9, 10]. Patients on chronic dialysis have an increased risk of cancer for several reasons, including the presence of chronic infection, a compromised immune system, nutritional deficiencies, and altered DNA repair [5]. There are also predisposing factors that contribute to the higher incidence of certain cancers in dialysis patients. Acquired renal cystic kidney disease increases the risk of renal cell carcinoma [11]. Long-term use of analgesics is a risk factor for transitional cell carcinoma of the bladder, ureter, and renal pelvis and for renal cell carcinoma [11-13]. In addition, the use of prolonged oral cyclophosphamide is a risk factor for bladder cancer [14]. Notably, there is an increased risk of several infection-associated cancers, such as the liver, cervix uteri, and tongue [5, 15-17]. The higher prevalence of infection with hepatitis $B$ and $C$ and human papillomavirus in HD patients probably accounts for the increased risks of these cancers [18-20]. In contrast, it remains controversial whether the risk of cancer of the lung, stomach, colon, breast, and corpus uteri is increased in patients with ESRD [5, 15-17]. In Japan, the most common cancer in ESRD patients is renal cell carcinoma, and the second is multiple myeloma, followed by liver and colon cancer in males and uterine cancer in females [21]. In contrast, while the most common cancer in ESRD patients in the USA is renal cell carcinoma as is in Japan, the second is prostate cancer in males and breast cancer in females [22]. In addition, whether cancer risk differs between transplant periods (under immunosuppression) and periods of dialysis after transplant failure (when immunosuppression is ceased or reduced) was investigated in a retrospective cohort of 8173 kidney transplant recipients [23]. In the multivariate analysis, incidences of non-Hodgkin lymphoma, lip cancer, and melanoma, which were included in infection- or immune-related cancers, were lower during dialysis after transplant failure whereas the incidence of thyroid cancer, which was shown to be included in ESRD-related cancer, was lower during periods of transplant function. More recently, a larger retrospective study including 202,195 kidney transplant candidates and recipients also examined whether cancer risk changes between 
transplant periods and periods of dialysis [22]. Due to the large sample size, this study provided more precise estimates of many individual cancers. In this study, individuals with transplants had higher adjusted risks of Kaposi sarcoma; non-Hodgkin lymphoma; Hodgkin lymphoma; melanoma; and cervical, anal, vaginal/vulvar, penile, otopharyngeal, liver, stomach, lung, lip, and non-epithelial skin cancers (which were included in infection- or immune-related cancers) than those with nonfunctioning kidneys on waiting lists and those with graft failure. In contrast, individuals with nonfunctioning kidneys had higher adjusted risks of kidney and thyroid cancers, which were considered to be related to ESRD. These studies indicated that the risk of infection- or immune-related cancers was higher in transplant recipients with functioning kidneys whereas the risk of ESRD-related cancers was higher in those under dialysis following kidney failure.

\section{Cancer screening in the ESRD population}

Standard malignancy-screening recommendations are based on the assumption that those screened would have a normal life span. It must be taken into consideration that benefit may be reduced or absent in individuals with low life expectancy. There is a general agreement that routine cancer screening is unlikely to result in a net benefit for individuals with limited life expectancy [24, 25]. This is reflected in the existing guidelines for various kinds of cancer, although different guidelines recommend different life expectancies or age cutoffs for cessation of cancer screening [26]. In the ESRD population, the expected remaining lifetime of most dialysis patients is shorter than the time lived after a cancer diagnosis, making cancer screening ineffective in terms of cost and survival benefit $[27,28]$. In a costeffectiveness analysis that compared cancer screening in patients on HD with screening in the general population, the screening benefits of mammography, Papanicolaou tests, flexible sigmoidoscopy, and serum prostatespecific antigen (PSA) levels were denied for the following reasons [6]: First, the costs per unit of survival benefit conferred by cancer screening were 1.6 to 19.3 times higher in patients with ESRD compared with those in the general population. Second, the net gain of life expectancy in patients with ESRD via these screening programs was calculated to be 5 days or less. Based on these results, it was concluded that routine cancer screening in the ESRD population was a relatively ineffective allocation of financial resources. Similar findings were also shown in a study evaluating the efficacy of breast and cervical cancer screening of Canadian women on HD [7].

It is important to recognize that the results obtained in these studies are average results for the ESRD population. It must not be concluded that no HD patients need cancer screening. Life expectancy for patients on dialysis would be better in the absence of coexisting complications, for example. In addition, malignancy is a common cause of death in patients receiving dialysis. In Japan, the percentage of HD patients who died of malignancies was $9.1 \%$ in total causes of death, ranking third after cardiac failure $(27.2 \%)$ and infectious diseases (20.3 \%) [29]. It should also be noted that patient survival in Japan has been better than that in the Western countries [30]. In addition, the magnitude of the association between mortality and cancer was greater in Japan than in Europe or the USA [30]. One cannot ignore the significant benefit to a patient who is diagnosed with a malignancy at an early stage by cancer screening and who could potentially receive curative therapy. These screening tests seem to be better limited to individualized patients with risk factors for malignancy and long life expectancy. The difference in cancer incidence between kidney transplant recipients and dialysis patients with nonfunctioning kidneys also suggests a need to individualize cancer screening $[22,23]$. In the CANcer and DialYsis (CANDY) study including 178 patients on chronic HD who subsequently had cancer, the mean and median times for cancer development after dialysis initiation were 30.8 and 13 months, respectively [8]. These results may indicate that cancer screening should be performed not long after the beginning of dialysis sessions, especially within the first few years. Further studies would help to establish cancer-screening protocols.

Although cancer-screening protocols in patients with ESRD have not been established, the efficacy of tumor markers has been relatively well examined in the ESRD population. Tumor markers have been used to follow the clinical course of certain cancers and also used as cancer-screening tools (Table 2). Since many tumor markers are not removed effectively by HD due to the relatively high molecular weight, serum levels are elevated after $\mathrm{HD}$ as a result of hemoconcentration, limiting their clinical effectiveness [31-33]. Total PSA, the sum of free and complex PSA, is used as a screening test for prostate cancer, usually in combination with digital rectal and ultrasound-guided examination. The percent of free PSA (fPSA) in total PSA (tPSA) is also used to enhance the discrimination of prostate cancer because the percent of fPSA is lower in men with prostate cancer than that in men with benign disorders [34]. tPSA is valid in dialysis patients, although fPSA is elevated and should not be used as a screening test for prostate cancer in dialysis patients [35]. Cancer antigen 125 (CA125 ) is a tumor marker for ovarian cancer but is also produced by mesothelial cells [36]. Serum CA-125 levels are elevated in HD patients with serosal fluid, pleural effusion, ascites, etc., and the results should be interpreted with caution [37]. In particular, this marker is a less 
Table 2 Summary of tumor markers in dialysis patients (modified from [31])

\begin{tabular}{ll}
\hline Tumor marker & Comments \\
\hline (A) Reliable in dialysis patients & \\
Total prostate-specific antigen (tPSA) & $\begin{array}{l}\text { Free PSA (fPSA) could be filtered through glomeruli, consistent with its low } \\
\text { molecular weight (28 kDa). Decreased GFR leads to an increased serum }\end{array}$ \\
& level of fPSA and higher percent fPSA to tPSA (\% \%PSA), since the level of \\
& tPSA does not differ compared with that of the controls [35]. Although not \\
& eliminated by low-flux membranes, fPSA is cleared by high-flux mem- \\
& branes [76], since molecules smaller than 5 and 50 kDa are filtered by low- \\
& flux and high-flux dialysis membranes, respectively [39].
\end{tabular}

$\beta$-human chorionic gonadotropin ( $\beta$-hCG), a-fetoprotein

(B) Falsely elevated in dialysis patients

Cancer antigen 125 (CA-125)

CA-125 is elevated in patients with peritoneal, pleural, or pericardial effusion [37]. In particular, CA-125 is falsely elevated as a result of nonspecific peritoneal irritation or peritonitis in patients undergoing peritoneal dialysis [38]. The serum concentration of CA-125 is increased during hemodialysis, probably due to hemoconcentration [32].

Carbohydrate antigen 19-9 (CA19-9), carcinoembryonic antigen (CEA), squamous cell carcinoma (SCC) antigen, and neuron-specific enolase (NSE)
Although the metabolism and clearance are not fully understood, previous studies revealed that the serum levels of CA19-9, CEA, SCC, and NSE are elevated in dialysis patients compared with patients with normal renal function [39-42]. An increase in the serum levels of these tumor markers is also found during hemodialysis, probably as a result of hemoconcentration [32]. It should be noted that SCC is cleared by high-flux membranes due to its molecular weight of 42 to $48 \mathrm{kDa}$, although it is not eliminated by low-flux membranes [33].

GFR glomerular filtration rate

accurate indicator of disease burden in patients undergoing peritoneal dialysis, since serum levels may be falsely elevated as a result of nonspecific peritoneal irritation or peritonitis [38]. Carbohydrate antigen 19-9 (CA19-9), carcinoembryonic antigen (CEA), squamous cell carcinoma (SCC) antigen, and neuron-specific enolase (NSE) have also been reported to be falsely elevated in dialysis patients compared with patients with normal renal function [39-42]. In contrast, $\alpha$-fetoprotein and $\beta$-human chorionic gonadotropin are reliable tumor markers in dialysis patients [43].

Although increased risks of colorectal and breast cancer have not been established in the ESRD population, as stated above, it has been emphasized that the results of fecal occult blood tests and mammography in patients with ESRD should be interpreted with caution. A positive stool guaiac test occurs at a higher frequency in dialysis patients due to an increased incidence of nonmalignant gastrointestinal abnormalities. In one series, the incidence of guaiac positive stools was three times higher in asymptomatic dialysis patients compared with non-ESRD controls [44]. However, the presence of a positive stool test in asymptomatic patients may enable the early detection of colorectal cancer. Mammography, a low-dose $\mathrm{x}$-ray system for examination of the breasts, aids in the earlier detection of breast cancer. The presence of benign vascular calcification in women with ESRD complicates mammography and leads to higher rates of false-positive results [45]. Since these cancers do not appear to be more common in patients with ESRD, patients on transplant waiting lists and patients with predisposing risk factors and long expected survival would be appropriate candidates for these screenings.

\section{Pharmacokinetics of anti-cancer agents in patients on hemodialysis}

Chemotherapy can be challenging when the patient's renal function is compromised. Although most anticancer agents are eliminated through the kidney, data on renal or dialysis clearance of these agents are scarce and often incomplete. The available recommendations for the appropriate dose adjustment of these agents for the ESRD population are based on data from a small series of case reports and expert opinions [46]. Many cytotoxic agents are excreted predominantly in the urine unchanged or as active/toxic metabolites. Thus, any reduction in renal clearance may result in the accumulation of potentially toxic components and overdose. For anuric HD patients, although the renal toxicity of chemotherapeutic agents is not a problem, the patients are exposed to all other potential dose-related systemic adverse effects. In addition, previous pharmacokinetic studies indicated that changes in the non-renal drug clearance occur in patients with ESRD [47]. Drug-metabolizing enzymes and transporters in other organs are considered to be affected by kidney diseases [47]. The influence of renal insufficiency on the renal and non-renal drug clearance of anti-cancer agents remains incompletely understood. The CANDY study included 178 patients on chronic HD who subsequently had cancer and 50 
patients $(28 \%)$ who had received anti-cancer drug treatment. Most of the patients received at least one anticancer agent for which specific attention was required in terms of drug dosage adjustments $(72 \%)$ and adequate timing of administration (82\%) [8]. A total of $44 \%$ of the treated patients developed iatrogenic toxicity: $34 \%$ related to drugs requiring dosage adjustment and $17 \%$ related to additional drugs with no existing management recommendations in dialysis patients. These results indicated that the lack of evidence concerning the use of systemic anti-cancer agents in renal insufficiency could lead to the inappropriate use of chemotherapy and fatal toxic effects in these patients. Although the pharmacokinetics of several chemotherapeutic agents in HD patients has been relatively well examined in case studies, the dose and timing of administration remain under debate. Previous case studies have examined different doses and intervals between HD and drug administration. HD immediately after dialyzable drug administration may improve tolerance although such protocols may lead to the reduction of anti-neoplastic efficacy and impose excess burden on the patient and treatment teams. In addition, a limited number of facilities can offer both HD and anti-cancer treatment on the same day. These limitations might deprive the patient of opportunities to receive optimal anti-cancer treatment. These social factors must also be taken into consideration in the establishment of anti-cancer therapeutic protocols.

This section focuses on the relatively well-described anti-cancer agents used in HD patients that have different main elimination organs, carboplatin (mainly eliminated by the kidney) and 5-fluorouracil (5-FU) (mainly eliminated by the liver), as well as tyrosine kinase inhibitors, that are frequently used in this new era of targeted anti-cancer therapy.

\section{Carboplatin}

One of the most widely used anti-cancer agents in HD patients is a platinum derivative, carboplatin [48, 49]. In patients with normal renal function, approximately $70 \%$ of the administered dose is excreted in the urine [50]. It has been shown that the target area under the curve (AUC) of carboplatin is associated with myelosuppressive and cytotoxic effects. Therefore, in clinical practice, the Calvert formula is well accepted for calculating the dose of carboplatin: dose $(\mathrm{mg})=\mathrm{AUC}(\mathrm{mg} / \mathrm{ml} \times \mathrm{min}) \times$ (glomerular filtration rate [GFR] $(\mathrm{ml} / \mathrm{min})+25)$ [50]. For patients with ESRD, many clinicians still use this formula with the assumption that the GFR can be almost equal to zero [51-53]. This AUC-targeted dose adjustment has permitted the individualization of the carboplatin dose for maximum effect with tolerable adverse effects. The HD setting after the administration of carboplatin influences the concentration of carboplatin in the plasma, since carboplatin can be removed from the plasma by HD [48]. The interval between the administration of carboplatin and HD varied between 1 and $24 \mathrm{~h}$ in previous studies (Table 3). In these studies, the AUCs varied depending on the doses and intervals between drug infusion and HD. Although there were variations between studies, the AUCs seemed to be higher when HD was started long after carboplatin infusion. A certain amount of carboplatin can be eliminated by performing HD in an early phase when the protein binding ratio is low [54]. This dialyzability may help to improve tolerance, although actual AUC values may be less reliable and more unstable when HD is performed immediately after the administration [51]. The protein binding of carboplatin, which hinders its elimination in HD, has been observed to increase by $50 \%$ after $24 \mathrm{~h}$ of administration [54]. Oguri et al. reported that the actual AUC values were approximately $20 \%$ higher than the target AUC when HD was performed $24 \mathrm{~h}$ after the administration of carboplatin [51]. Particular attention should be paid to the development of adverse events such as hematological toxicities when there is a long interval between carboplatin administration and HD.

\section{5-FU}

5-FU is mainly metabolized via redihydropyrimidine dehydrogenase in the liver and other tissues, and only a small amount of 5-FU (approximately $10 \%$ of the administered dose) is eliminated unchanged by the kidney [55]. In line with its short elimination half-life (20 min), 5 -FU is given by intravenous continuous infusion over several days as well as by intravenous bolus infusion, allowing the easy determination of systemic clearance based on steady-state plasma concentrations [56]. In a previous case report, a weekly regimen composed of CPT-11 $\left(50 \mathrm{mg} / \mathrm{m}^{2}\right)$ followed by leucovorin $\left(10 \mathrm{mg} / \mathrm{m}^{2}\right)$ and 5 -FU $\left(400 \mathrm{mg} / \mathrm{m}^{2}\right)$ was administered immediately after HD. Although the dose of $400 \mathrm{mg} / \mathrm{m}^{2} 5$-FU was reduced compared with that of patients with normal renal function, the bolus intravenous injection of 5-FU to HD patients after HD sessions provided a blood concentration profile similar to that in normal subjects [57]. The patient presented with grade 3 hematological toxicity that was recovered by granulocyte colony-stimulating factor. In another study, the intravenous bolus and continuous infusion of 5-FU was included in the FOLFOX 4 regimen; the doses of oxaliplatin and 5-FU were both reduced from those in the original FOLFOX 4 regimen. The dose of oxaliplatin was $40 \mathrm{mg} / \mathrm{m}^{2}$, and 5 -FU was given as a bolus of $300 \mathrm{mg} / \mathrm{m}^{2}$ followed by a continuous intravenous infusion of $500 \mathrm{mg} / \mathrm{m}^{2}$ [58]. HD was performed $1 \mathrm{~h}$ after the administration of oxaliplatin on day 1 and was repeated 2 days later after the completion of 
Table 3 Intervals between carboplatin infusion and HD and AUCs of free carboplatin in previous studies of carboplatin-based chemotherapy in HD patients

\begin{tabular}{|c|c|c|c|c|c|}
\hline & Number of patients & Disease & Carboplatin dose & $\begin{array}{l}\text { Interval between } \\
\text { carboplatin } \\
\text { infusion and } \\
\text { hemodialysis (h) }\end{array}$ & $\begin{array}{l}\text { AUC }(\mathrm{mg} \times \mathrm{min} / \mathrm{ml}) \\
\text { of free carboplatin }\end{array}$ \\
\hline \multicolumn{6}{|c|}{ (A) Hemodialysis was initiated soon after carboplatin infusion (1 2 h after infusion). } \\
\hline \multirow[t]{2}{*}{ Kurata et al. (1994) [77] } & 1 & Ovarian carcinoma & 240 mg/m² (cycle 1) & 1 & 3.14 \\
\hline & & & 240 mg/m² (cycle 2) & 2 & 5.09 \\
\hline \multirow[t]{2}{*}{ Suzuki et al. (1997) [78] } & 1 & Merkel cell carcinoma & 150 mg (cycle 1) & 1 & 4.6 \\
\hline & & & 150 mg (cycle 2) & 2 & 4.8 \\
\hline Watanabe et al. (2002) [52] & 1 & Ovarian carcinoma & 125 mg (cycle 1) & 1.5 & 2.21 \\
\hline Furuya et al. (2003) [79] & 1 & Urothelial carcinoma & $125 \mathrm{mg}$ & 1 & 2.44 \\
\hline \multirow[t]{2}{*}{ Takezawa et al. (2008) [80] } & 1 & SCLC & 250 mg/m² (cycle 1) & 1 & 4.10 \\
\hline & & & 275 mg/m² (cycle 2) & 1 & 4.16 \\
\hline Kamata et al. (2009) [81] & 1 & $\mathrm{NSCLC}$ & $150 \mathrm{mg} / \mathrm{m}^{2}$ & 1 & 4.9 \\
\hline Yoshida et al. (2009) [82] & 1 & Ovarian carcinoma & $125 \mathrm{mg}$ & 1 & 0.98 \\
\hline \multirow[t]{3}{*}{ Kondo et al. (2012) [83] } & 1 & Cancer of unknown primary & 125 mg (cycle 1) & 1 & 3.03 \\
\hline & & & 125 mg (cycle 2) & 1 & 3.44 \\
\hline & & & 125 mg (cycle 3) & 1 & 3.5 \\
\hline \multirow[t]{2}{*}{ Hiraike et al. (2012) [54] } & 1 & $\mathrm{SCLC}$ & 480 mg (cycle 1) & 1 & 13.45 \\
\hline & & & 170 mg (cycle 2) & 1 & 5.74 \\
\hline \multicolumn{6}{|c|}{ (B) Hemodialysis was initiated long after carboplatin infusion (16 24 h after infusion). } \\
\hline \multirow[t]{2}{*}{ Motzer et al. (1990) [84] } & 2 & Germ cell tumor & $100 \mathrm{mg} / \mathrm{m}^{2}$ & 24 & 6.7 \\
\hline & & Germ cell tumor & $100 \mathrm{mg} / \mathrm{m}^{2}$ & 24 & 6.9 \\
\hline \multirow[t]{3}{*}{ Chatelut et al. (1994) [48] } & 1 & Ovarian carcinoma & 100 mg (cycle 1) & 24 & 3.5 \\
\hline & & & 150 mg (cycle 2) & 24 & 6.7 \\
\hline & & & 150 mg (cycle 3) & 24 & 6.06 \\
\hline \multirow[t]{3}{*}{ Watanabe et al. (2002) [52] } & 1 & Ovarian carcinoma & 125 mg (cycle 2) & 16 & 4.43 \\
\hline & & & 125 mg (cycle 3) & 16 & 4.75 \\
\hline & & & 125 mg (cycle 4) & 16 & 4.13 \\
\hline \multirow[t]{2}{*}{ Yokoyama et al. (2006) [85] } & 1 & Ovarian carcinoma & 200 mg (cycle 1) & 24 & 8.03 \\
\hline & & & 200 mg (cycle 2) & 16 & 5.69 \\
\hline \multirow[t]{2}{*}{ Oguri et al. (2010) [51] } & 2 & NSCLC & 100 mg & 24 & 4.7 \\
\hline & & Ovarian cancer & $125 \mathrm{mg}$ & 24 & 6.1 \\
\hline \multirow[t]{4}{*}{ Kodama et al. (2010) [86] } & 1 & Ovarian carcinoma & 100 mg (cycle 1) & 24 & 3.48 \\
\hline & & & 150 mg (cycle 2) & 24 & 4.23 \\
\hline & & & 175 mg (cycle 3) & 24 & 5.55 \\
\hline & & & 150 mg (cycle 4) & 24 & 4.59 \\
\hline
\end{tabular}

SCLC small cell lung cancer, NSCLC non-small cell lung cancer

drug administration. Vomiting (grade 2), anorexia, and leukopenia (both grade 3) were observed after the first treatment. A total of four courses were administered thereafter by reducing the dose of oxaliplatin to $32 \mathrm{mg} /$ $\mathrm{m}^{2}$, the intravenous bolus of 5 - $\mathrm{FU}$ to $240 \mathrm{mg} / \mathrm{m}^{2}$, and the continuous infusion of $5-\mathrm{FU}$ to $400 \mathrm{mg} / \mathrm{m}^{2}$. After the dose reduction, no adverse events were observed other than anorexia (grade 1). Although the dose reduction of 5-FU was not recommended in previous studies $[46,59,60]$, these studies indicated that a further accumulation of cases is needed to establish the optimal dose in HD patients. Particular attention should also be paid to the development of 5-FU-induced encephalopathy, especially when a higher dose of 5 -FU is administered. Ammonia, a metabolite of 5-FU, accumulates in large amounts after the administration of high-dose 5- 
FU [61, 62]. Renal dysfunction may be an aggravating factor of hyperammonemia related to 5 -FU infusion [63, 64]. It has been suggested that a large amount of fluoroacetate, a final metabolite of 5-FU, could be accumulated in patients with renal dysfunction and inhibit the Krebs cycle. This could cause impairment in the ATPdependent urea cycle, resulting in lactic acidosis and further exacerbation of a hyperammonemic state [62, 64]. The direct toxicity of alpha-fluoro-beta-alanine (FBAL), an intermediate metabolite of 5-FU, on myelin was also proposed as the cause of 5-FU-induced encephalopathy [65]. In HD patients, FBAL, which is mainly excreted by the kidney with minor elimination via bile and the bowel, was reported to accumulate approximately twofold higher than expected in patients with normal renal function [66]. The authors also reported that FBAL could be eliminated by HD, suggesting that more intensive dialysis treatment may be useful for improving the elimination of FBAL to minimize the possible risks of FBAL-mediated toxicity.

\section{Tyrosine kinase inhibitors}

Several studies have recently examined the pharmacokinetics of tyrosine kinase inhibitors such as sunitinib, imatinib, sorafenib, and erlotinib in HD patients [6771]. After oral administration, these agents are primarily metabolized in the liver by cytochrome CYP3A4, with only a small proportion excreted in the urine [72, 73]. These agents were reported to be minimally affected by HD [67, 69-71]. Therefore, administration can take place anytime, independent of the HD sessions. Previous studies have shown that treatment with these agents is well tolerated and has good efficacy in patients with ESRD [71, 72, 74, 75]. However, one study showed that dose reduction or discontinuation of sorafenib was frequently needed (even with lower concentrations of sorafenib) in patients with metastatic renal cell carcinoma undergoing HD [70]. Serious adverse events were found in 9 of 10 patients, including a grade 5 subarachnoid hemorrhage and a grade 4 cerebellar hemorrhage. The authors suggested that the patients on chronic HD might be susceptible to the unfavorable effects of antiangiogenic agents like sorafenib due to their vulnerable vascular tissues. Treatment of HD patients with tyrosine kinase inhibitors appears to be feasible, but special attention should be paid to the occurrence of serious adverse events, considering the underlying risk factors of HD patients.

\section{Conclusions}

Since a growing number of patients with ESRD are developing cancer, it is essential to establish evidencebased recommendations for cancer screening and anticancer treatment in the ESRD population. This review provided recent evidence for cancer risk and screening in the ESRD population. There is a pressing need for clinical trials that are designed to identify those who would benefit from cancer screening in this population. This review article also addressed the pharmacokinetics of representative anti-cancer agents, carboplatin, 5-FU, and tyrosine kinase inhibitors. Although the optimal interval between dialysis sessions and carboplatin infusion has not been fully investigated, the usefulness of the administration of carboplatin to HD patients has been documented in previous reports, in which the dose was calculated by the Calvert formula, assuming the GFR to be zero. While the dose reduction of 5-FU may not be recommended in previous studies, the metabolites of 5FU such as ammonia, fluoroacetate, and FBAL can be accumulated in HD patients, indicating the need for the reassessment of the optimal dose of 5-FU in $\mathrm{HD}$ patients. Although treatment with tyrosine kinase inhibitors at the same dose as in normal subjects is often feasible in HD patients, it should be kept in mind that HD patients might be more susceptible to adverse effects due to underlying risk factors. The data are limited, mostly consisting of single case studies that have examined different chemotherapy protocols. Future studies employing the same regimen for larger patient populations are warranted. The accumulation of studies will lead to the establishment of optimal therapeutic strategies for patients suffering from cancer and kidney disease.

\section{Competing interests \\ MY is on the advisory board of Astellas and receives research grants from Astellas, Chugai Pharmaceutical Co. (Tokyo, Japan), Daiichi Sankyo, \\ Fujiyakuhin, Kyowa Hakko Kirin, Mitsubishi Tanabe Pharma Corporation, MSD, Nippon Boehringer Ingelheim, and Torii.}

\section{Authors' contributions}

All authors read and approved the final manuscript.

\section{Funding}

Our department is supported by Grants-in-Aid for Scientific Research (B 26293202 to MY, C 25461221 to TM, Houga 26670430 to MY) from the Japan Society for the Promotion of Science (JSPS), a CREST award from the Japan Science and Technology Agency (to MY), a grant from the Japanese Association of Dialysis Physicians (JADP Grant 2014-11 to TM), a grant from the Kidney Foundation of Japan (JKF14-2 to TM), and Integration Research for Agriculture and Interdisciplinary Fields from the National Agriculture and Food Research Organization (to MY)

\section{Author details}

${ }^{1}$ Department of Nephrology, Graduate School of Medicine, Kyoto University, 54 Shogoin-Kawaracho, Sakyo-ku, Kyoto 606-8507, Japan. ²Department of Therapeutic Oncology, Graduate School of Medicine, Kyoto University, Kyoto, Japan.

Received: 7 February 2016 Accepted: 6 May 2016

Published online: 01 August 2016

\section{References}

1. Kitai Y, Matsubara T, Yanagita M. Onco-nephrology: current concepts and future perspectives. Jpn J Clin Oncol. 2015;45:617-28. 
2. Berns JS, Rosner MH. Onco-nephrology: what the nephrologist needs to know about cancer and the kidney. Clin J Am Soc Nephrol. 2012;7:1691.

3. Cosmai L, Porta C, Gallieni M, Perazella MA. Onco-nephrology: a decalogue. Nephrol Dial Transplant. 2016;31:515-19.

4. Buccianti G, Maisonneuve P, Ravasi B, Cresseri D, Locatelli F, Boyle P. Cancer among patients on renal replacement therapy: a population-based survey in Lombardy, Italy. Int J Cancer. 1996;66:591-3.

5. Maisonneuve P, Agodoa L, Gellert R, Stewart JH, Buccianti G, Lowenfels AB, et al. Cancer in patients on dialysis for end-stage renal disease: an international collaborative study. Lancet. 1999;354:93-9.

6. Chertow GM, Paltiel AD, Owen WF, Lazarus JM. Cost-effectiveness of cancer screening in end-stage renal disease. Arch Intern Med. 1996;156:1345-50.

7. Kajbaf S, Nichol G, Zimmerman D. Cancer screening and life expectancy of Canadian patients with kidney failure. Nephrol Dial Transplant. 2002:17:1786-9.

8. Janus $\mathrm{N}$, Launay-Vacher $\mathrm{V}$, Thyss A, Boulanger $\mathrm{H}$, Moranne $\mathrm{O}$, Islam MS, et al. Management of anticancer treatment in patients under chronic dialysis: results of the multicentric CANDY (CANcer and DialYsis) study. Ann Oncol. 2013;24:501-7.

9. Birkeland SA, Løkkegaard H, Storm HH. Cancer risk in patients on dialysis and after renal transplantation. Lancet. 2000;355:1886-7.

10. Vajdic CM, McDonald SP, McCredie MR, van Leeuwen MT, Stewart JH, Law $M$, et al. Cancer incidence before and after kidney transplantation. JAMA 2006;296:2823-31.

11. Stewart JH, Buccianti G, Agodoa L, Gellert R, McCredie MR, Lowenfels AB, et al. Cancers of the kidney and urinary tract in patients on dialysis for end-stage renal disease: analysis of data from the United States, Europe, and Australia and New Zealand. J Am Soc Nephrol. 2003;14:197-207.

12. Linet MS, Chow WH, McLaughlin JK, Wacholder S, Yu MC, Schoenberg JB, et al. Analgesics and cancers of the renal pelvis and ureter. Int J Cancer. 1995;62:15-8.

13. Gago-Dominguez M, Yuan JM, Castelao JE, Ross RK, Yu MC. Regular use of analgesics is a risk factor for renal cell carcinoma. Br J Cancer. 1999;81:542-8.

14. Talar-Williams C, Hijazi YM, Walther MM, Linehan WM, Hallahan CW, Lubensky I, et al. Cyclophosphamide-induced cystitis and bladder cancer in patients with Wegener granulomatosis. Ann Intern Med. 1996;124:477-84.

15. Heidland A, Bahner U, Vamvakas S. Incidence and spectrum of dialysisassociated cancer in three continents. Am J Kidney Dis. 2000;35:347-51. discussion 352-343.

16. Shebl FM, Warren JL, Eggers PW, Engels EA. Cancer risk among elderly persons with end-stage renal disease: a population-based case-contro study. BMC Nephrol. 2012;13:65

17. Lin MY, Kuo MC, Hung CC, Wu WJ, Chen LT, Yu ML, et al. Association of dialysis with the risks of cancers. PLoS One. 2015;10:e0122856

18. Niu MT, Coleman PJ, Alter MJ. Multicenter study of hepatitis C virus infection in chronic hemodialysis patients and hemodialysis center staff members. Am J Kidney Dis. 1993;22:568-73.

19. Fabrizi F, Bunnapradist S, Martin P. HBV infection in patients with end-stage renal disease. Semin Liver Dis. 2004;24 Suppl 1:63-70.

20. Fairley CK, Chen S, Tabrizi SN, McNeil J, Becker G, Walker R, et al. Prevalence of HPV DNA in cervical specimens in women with renal transplants: a comparison with dialysis-dependent patients and patients with renal impairment. Nephrol Dial Transplant. 1994;9:416-20.

21. Kaidu K, Tanaka Y, Tokui N. Shindan to Chiryou (in Japanese). 2013;101:1071-76 http://shindan.co.jp/books/index.php?menu=10\&cd=2130700\&kbn=2\#ronbun.

22. Yanik EL, Clarke CA, Snyder JJ, Pfeiffer RM, Engels EA. Variation in cancer incidence among patients with ESRD during kidney function and nonfunction intervals. J Am Soc Nephrol. 2015; epub ahead of print.

23. van Leeuwen MT, Webster AC, McCredie MR, Stewart JH, McDonald SP, Amin J, et al. Effect of reduced immunosuppression after kidney transplant failure on risk of cancer: population based retrospective cohort study. BMJ. 2010;340:c570

24. Woolf $\mathrm{SH}$, Harris R. The harms of screening: new attention to an old concern. JAMA. 2012;307:565-6.

25. Walter LC, Covinsky KE. Cancer screening in elderly patients: a framework for individualized decision making. JAMA. 2001;285:2750-6.

26. Royce TJ, Hendrix LH, Stokes WA, Allen IM, Chen RC. Cancer screening rates in individuals with different life expectancies. JAMA Intern Med. 2014;174:1558-65.

27. Holley JL. Preventive medical screening is not appropriate for many chronic dialysis patients. Semin Dial. 2000;13:369-71.
28. LeBrun CJ, Diehl LF, Abbott KC, Welch PG, Yuan CM. Life expectancy benefits of cancer screening in the end-stage renal disease population. Am J Kidney Dis. 2000;35:237-43.

29. Nakai S, Hanafusa N, Masakane I, Taniguchi M, Hamano T, Shoji T, et al. An overview of regular dialysis treatment in Japan (as of 31 December 2012). Ther Apher Dial. 2014;18:535-602.

30. Goodkin DA, Bragg-Gresham JL, Koenig KG, Wolfe RA, Akiba T, Andreucci $V E$, et al. Association of comorbid conditions and mortality in hemodialysis patients in Europe, Japan, and the United States: the Dialysis Outcomes and Practice Patterns Study (DOPPS). J Am Soc Nephrol. 2003;14:3270-7.

31. Holley JL. Screening, diagnosis, and treatment of cancer in long-term dialysis patients. Clin J Am Soc Nephrol. 2007;2:604-10.

32. Odagiri E, Jibiki K, Takeda M, Sugimura H, Iwachika C, Abe $Y$, et al. Effect of hemodialysis on the concentration of the seven tumor markers carcinoembryonic antigen, alpha-fetoprotein, squamous cell carcinomarelated antigen, neuron-specific enolase, CA 125, CA 19-9 and CA 15-3 in uremic patients. Am J Nephrol. 1991;11:363-8.

33. Kashiwabara K, Nakamura H, Yagyu H, Kishi K, Matsuoka T, Esaki T. Changes in squamous cell carcinoma-related antigen levels before and after hemodialysis in relation to the model of dialyzer employed. Intern Med. 2000;39:291-5.

34. Christensson A, Björk T, Nilsson O, Dahlén U, Matikainen MT, Cockett AT, et al. Serum prostate specific antigen complexed to alpha 1antichymotrypsin as an indicator of prostate cancer. J Urol. 1993;150:100-5.

35. Bruun L, Björk T, Lilja H, Becker C, Gustafsson O, Christensson A. Percent-free prostate specific antigen is elevated in men on haemodialysis or peritoneal dialysis treatment. Nephrol Dial Transplant. 2003;18:598-603.

36. Zeimet AG, Marth C, Offner FA, Obrist P, Uhl-Steidl M, Feichtinger $\mathrm{H}$, et al. Human peritoneal mesothelial cells are more potent than ovarian cancer cells in producing tumor marker CA-125. Gynecol Oncol. 1996;62:384-9.

37. Sevinc A, Buyukberber S, Sari R, Kiroglu Y, Turk HM, Ates M. Elevated serum CA-125 levels in hemodialysis patients with peritoneal, pleural, or pericardial fluids. Gynecol Oncol. 2000;77:254-7.

38. Bastani B, Chu N. Serum CA-125 level in end-stage renal disease patients maintained on chronic peritoneal dialysis or hemodialysis: the effect of continuous presence of peritoneal fluid, peritonitis, and peritoneal catheter implantation. Am J Nephrol. 1995;15:468-72.

39. Xiaofang $Y$, Yue $Z$, Xialian $X$, Zhibin $Y$. Serum tumour markers in patients with chronic kidney disease. Scand J Clin Lab Invest. 2007;67:661-7.

40. Filella X, Cases A, Molina R, Jo J, Bedini JL, Revert L, et al. Tumor markers in patients with chronic renal failure. Int J Biol Markers. 1990;5:85-8.

41. Arik N, Adam B, Akpolat T, Haşil K, Tabak S. Serum tumour markers in renal failure. Int Urol Nephrol. 1996;28:601-4.

42. Tzitzikos G, Saridi M, Filippopoulou T, Makri A, Goulioti A, Stavropoulos T, et al. Measurement of tumor markers in chronic hemodialysis patients. Saudi J Kidney Dis Transpl. 2010;21:50-3.

43. Arican A, Ozdemir N, Sezer S, Erten Y, Güz G, Turan M, et al. Tumor markers in hemodialysis patients. Transplant Proc. 1999;31:3367-8.

44. Ajam M, Ramanujam LS, Gandhi VC, Leehey DJ, Ing TS, Schnell TG, et al. Colon-cancer screening in dialysis patients. Artif Organs. 1990;14:95-7.

45. Castellanos M, Varma S, Ahern K, Grosso SJ, Buchbinder S, D'Angelo D, et al Increased breast calcifications in women with ESRD on dialysis: implications for breast cancer screening. Am J Kidney Dis. 2006:48:301-6.

46. Janus N, Thariat J, Boulanger H, Deray G, Launay-Vacher V. Proposal for dosage adjustment and timing of chemotherapy in hemodialyzed patients. Ann Oncol. 2010;21:1395-403.

47. Nolin TD, Unruh ML. Clinical relevance of impaired nonrenal drug clearance in ESRD. Semin Dial. 2010;23:482-5.

48. Chatelut E, Rostaing L, Gualano V, Vissac T, De Forni M, Ton-That $H$, et al. Pharmacokinetics of carboplatin in a patient suffering from advanced ovarian carcinoma with hemodialysis-dependent renal insufficiency. Nephron. 1994:66:157-61.

49. English MW, Lowis SP, Peng B, Boddy A, Newell DR, Price L, et al. Pharmacokinetically guided dosing of carboplatin and etoposide during peritoneal dialysis and haemodialysis. Br J Cancer. 1996;73:776-80.

50. Calvert AH, Newell DR, Gumbrell LA, O'Reilly S, Burnell M, Boxall FE, et al. Carboplatin dosage: prospective evaluation of a simple formula based on renal function. J Clin Oncol. 1989:7:1748-56.

51. Oguri T, Shimokata T, Inada M, Ito I, Ando Y, Sasaki Y, et al. Pharmacokinetic analysis of carboplatin in patients with cancer who are undergoing hemodialysis. Cancer Chemother Pharmacol. 2010;66:813-7. 
52. Watanabe M, Aoki Y, Tomita M, Sato T, Takaki Y, Kato N, et al. Paclitaxel and carboplatin combination chemotherapy in a hemodialysis patient with advanced ovarian cancer. Gynecol Oncol. 2002;84:335-8.

53. Jeyabalan N, Hirte HW, Moens F. Treatment of advanced ovarian carcinoma with carboplatin and paclitaxel in a patient with renal failure. Int J Gynecol Cancer. 2000;10:463-8.

54. Hiraike M, Hiraki Y, Misumi N, Hanada K, Tsuji Y, Kamimura H, et al. Pharmacokinetics of carboplatin in a hemodialysis patient with small-cell lung cancer. Cancer Chemother Pharmacol. 2012;69:845-8.

55. Heggie GD, Sommadossi JP, Cross DS, Huster WJ, Diasio RB. Clinical pharmacokinetics of 5-fluorouracil and its metabolites in plasma, urine, and bile. Cancer Res. 1987;47:2203-6.

56. Paci A, Veal G, Bardin C, Levêque D, Widmer N, Beijnen J, et al. Review of therapeutic drug monitoring of anticancer drugs part 1-cytotoxics. Eur J Cancer. 2014;50:2010-9.

57. Akiyama S, Nakayama H, Takami H, Gotoh H, Gotoh Y. Pharmacodynamic study of the Saltz regimen for metastatic colorectal cancer in a hemodialyzed patient. Chemotherapy. 2007;53:418-21.

58. Ohnishi T, Kanoh T, Shiozaki K, Kimura Y, Iwazawa T, Tono T, et al. FOLFOX 4 in a patient with metastatic colorectal cancer on hemodialysis due to chronic renal failure. Gan To Kagaku Ryoho. 2007;34:1299-302.

59. Launay-Vacher V, Oudard S, Janus N, Gligorov J, Pourrat X, Rixe O, et al. Prevalence of renal insufficiency in cancer patients and implications for anticancer drug management: the renal insufficiency and anticancer medications (IRMA) study. Cancer. 2007;110:1376-84.

60. Lichtman SM, Wildiers H, Launay-Vacher V, Steer C, Chatelut E, Aapro M. International Society of Geriatric Oncology (SIOG) recommendations for the adjustment of dosing in elderly cancer patients with renal insufficiency. Eur J Cancer. 2007:43:14-34.

61. Kwon KA, Kwon HC, Kim MC, Kim SH, Oh SY, Lee S, et al. A case of 5fluorouracil induced encephalopathy. Cancer Res Treat. 2010;42:118-20.

62. Koenig $\mathrm{H}$, Patel A. Biochemical basis for fluorouracil neurotoxicity. The role of Krebs cycle inhibition by fluoroacetate. Arch Neurol. 1970;23:155-60.

63. Stéphan F, Etienne MC, Wallays C, Milano G, Clergue F. Depressed hepatic dihydropyrimidine dehydrogenase activity and fluorouracil-related toxicities. Am J Med. 1995;99:685-8.

64. Yeh $\mathrm{KH}$, Cheng AL. High-dose 5-fluorouracil infusional therapy is associated with hyperammonaemia, lactic acidosis and encephalopathy. Br J Cancer. 1997;75:464-5.

65. Okeda R, Karakama T, Kimura S, Toizumi S, Mitsushima T, Yokoyama Y. Neuropathologic study on chronic neurotoxicity of 5-fluorouracil and its masked compounds in dogs. Acta Neuropathol. 1984;63:334-43.

66. Rengelshausen J, Hull WE, Schwenger V, Göggelmann C, Walter-Sack I, Bommer J. Pharmacokinetics of 5-fluorouracil and its catabolites determined by $19 \mathrm{~F}$ nuclear magnetic resonance spectroscopy for a patient on chronic hemodialysis. Am J Kidney Dis. 2002:39:E10.

67. Izzedine H, Etienne-Grimaldi MC, Renée N, Vignot S, Milano G. Pharmacokinetics of sunitinib in hemodialysis. Ann Oncol. 2009;20:190-2.

68. Thiery-Vuillemin A, Montange D, Kalbacher E, Maurina T, Nguyen T, Royer B, et al. Impact of sunitinib pharmacokinetic monitoring in a patient with metastatic renal cell carcinoma undergoing hemodialysis. Ann Oncol. 2011;22:2152-4.

69. Pappas P, Karavasilis V, Briasoulis E, Pavlidis N, Marselos M. Pharmacokinetics of imatinib mesylate in end stage renal disease. A case study. Cancer Chemother Pharmacol. 2005;56:358-60.

70. Kennoki T, Kondo T, Kimata N, Murakami J, Ishimori I, Nakazawa H, et al. Clinical results and pharmacokinetics of sorafenib in chronic hemodialysis patients with metastatic renal cell carcinoma in a single center. Jpn J Clin Oncol. 2011:41:647-55

71. Togashi Y, Masago K, Fukudo M, Terada T, Ikemi Y, Kim YH, et al. Pharmacokinetics of erlotinib and its active metabolite OSI-420 in patients with non-small cell lung cancer and chronic renal failure who are undergoing hemodialysis. J Thorac Oncol. 2010;5:601-5.

72. Masini C, Sabbatini R, Porta C, Procopio G, Di Lorenzo G, Onofri A, et al. Use of tyrosine kinase inhibitors in patients with metastatic kidney cancer receiving haemodialysis: a retrospective Italian survey. BJU Int. 2012;110:692-8.

73. Hidalgo M. Erlotinib: preclinical investigations. Oncology (Williston Park). 2003;17:11-6.

74. Ozdemir E, Koc Y, Kansu E. Successful treatment of chronic myeloid leukemia with imatinib mesylate in a patient with chronic renal failure on hemodialysis. Am J Hematol. 2006:81:474.
75. Rey PM, Villavicencio $H$. Sorafenib: tolerance in patients on chronic hemodialysis: a single-center experience. Oncology. 2008;74:245-6.

76. Djavan B, Shariat S, Ghawidel K, Güven-Marberger K, Remzi M, Kovarik J, et al. Impact of chronic dialysis on serum PSA, free PSA, and free/total PSA ratio: is prostate cancer detection compromised in patients receiving longterm dialysis? Urology. 1999:53:1169-74.

77. Kurata H, Yoshiya N, Ikarashi H, Kaneko T, Kodama S, Tanaka K, et al. Pharmacokinetics of carboplatin in a patient under hemodialysis. Gan To Kagaku Ryoho. 1994;21:547-50.

78. Suzuki S, Koide M, Sakamoto S, Matsuo T. Pharmacokinetics of carboplatin and etoposide in a haemodialysis patient with Merkel-cell carcinoma. Nephrol Dial Transplant. 1997;12:137-40.

79. Furuya Y, Takihana Y, Araki I, Tanabe N, Takeda M. Pharmacokinetics of paclitaxel and carboplatin in a hemodialysis patient with metastatic urothelial carcinoma-a case report. Gan To Kagaku Ryoho. 2003;30:1017-20.

80. Takezawa K, Okamoto I, Fukuoka M, Nakagawa K. Pharmacokinetic analysis of carboplatin and etoposide in a small cell lung cancer patient undergoing hemodialysis. J Thorac Oncol. 2008;3:1073-5.

81. Kamata H, Asano K, Soejima K, Shirahata T, Nakatani M, Inamoto H, et al. Appropriate hemodialysis scheduling based on therapeutic drug monitoring of carboplatin in a patient with lung cancer and chronic renal failure. Gan To Kagaku Ryoho. 2009:36:1529-32.

82. Yoshida H, Sumi T, Abe K, Ishiko O. Pharmacokinetics of paclitaxel and carboplatin in a hemodialysis patient with advanced ovarian cancer. Eur J Gynaecol Oncol. 2009;30:583-5.

83. Kondo M, Kuroda J, Ikai Y, Hayashi R, Uegaki S, Yoshida T, et al. Safe and effective administration of carboplatin-based chemotherapy in a patient undergoing hemodialysis with cancer of unknown primary by monitoring observed AUC of carboplatin - a case report. Gan To Kagaku Ryoho. 2012 39:1749-52.

84. Motzer RJ, Niedzwiecki D, Isaacs M, Menendez-Botet C, Tong WP, Flombaum C, et al. Carboplatin-based chemotherapy with pharmacokinetic analysis for patients with hemodialysis-dependent renal insufficiency. Cancer Chemother Pharmacol. 1990;27:234-8.

85. Yokoyama Y, Futagami M, Higuchi T, Mizunuma H. Pharmacokinetic analysis of paclitaxel and carboplatin in a patient with advanced ovarian cancer during hemodialysis_case report. Eur J Gynaecol Oncol. 2006:27:437-9.

86. Kodama J, Sasaki A, Masahiro S, Seki N, Kusumoto T, Nakamura K, et al. Pharmacokinetics of combination chemotherapy with paclitaxel and carboplatin in a patient with advanced epithelial ovarian cancer undergoing hemodialysis. Oncol Lett. 2010;1:511-3.

\section{Submit your next manuscript to BioMed Central and we will help you at every step:}

- We accept pre-submission inquiries

- Our selector tool helps you to find the most relevant journal

- We provide round the clock customer support

- Convenient online submission

- Thorough peer review

- Inclusion in PubMed and all major indexing services

- Maximum visibility for your research

Submit your manuscript at www.biomedcentral.com/submit 